\title{
2章 HTML5によるメディア配信の標準化動向
}

キーワード：Web標準，Open Web Platform，HTML5, MSE， EME

\section{1. まえがき}

時代とともにWebで扱うコンテンツは多様化しマルチメ ディア対応かつインタラクティブなコンテンツの需要が飛 躍的に増加してきた。 その結果, Webコンテンツは, 単な る「Webページ」から「Webアプリケーション」へと変遷を 遂げた。本稿では，まず，Web技術とWorld Wide Web Consortium (W3C) によるその国際的標準化について概観 した上で，マルチメディア対応かつインタラクティブな Webアプリケーション開発のプラットフォームとして利用 されているHTML5について解説する．さらに，近年ます ます広がりを見せるWebアプリケーション用のさまざまな 端末機器の例としてテレビに着目した上で, HTML5によ るメディア配信の標準化動向について説明するとともに, 今後の展望について述べる.

\section{Web技術とW3Cによる国際標準化}

\subsection{Web技術の変遷}

Webは世界中で共通的に利用されるがゆえに，その相互 運用性 (Interoperability), 国際化 (Internationalization), 入出力方法の多様性 (Multi-Modality), および利用者への 親和性 (Accessibility) を保証する必要があり, そのために, W3C1) 等による国際的な技術標準化が継続して行われてい る. そのWebへのアクセス方法としてWebブラウザが開 発され, 各種端末上の表示装置およびブラウザ・ソフト ウェアの差分を吸収するため, そして開発者が容易にWeb アプリケーションの開発を行うことができるように, Hypertext Markup Language (HTML) 2) 4) が標準化され利 用されてきた。一方で，時代とともにWebで扱うコンテン ツは多様化し, マルチメディア対応かつインタラクティブ なコンテンツの需要が飛躍的に増加した結果, Webコンテ ンツは，単なる「Webページ」から「Webアプリケーション」

†慶應義塾大学大学院政策・メディア研究科/World Wide Web Consortium (W3C)

"Media Distribution Using HTML5 and Related Web Standards" by Kazuyuki Ashimura (Keio University Graduate School of Media and Governance, Kanagawa/World Wide Web Consortium (W3C))
へと変遷を遂げ，さらに，その利用環境も携帯機器や家電 機器へと範囲を広げており，これにより，Webコンテンッ を従来の方法で表現することが難しくなってきている.

開発者はこのようなWeb利用の進化に合わせるため，独 自の手法を使って対応するようになっていったが，それが 逆にコンテンツ普及の妨げになるという面も合わせ持って いた。 そこで，2008年に新しいWebアプリケーション記 述言語として HTML55) 6) の策定が開始され，近年ではPC のみならず, iPhone, Android等, いわゆるスマートフォ ンを含めた各種デバイスにおけるWebアプリケーションの 利用が広がっている.

\subsection{W3CによるWeb技術の標準化}

W3 $\mathrm{C}^{1)}$ は, Webの可能性を最大限に導き出すことを目的 として，Web技術発明者であるTim Berners-Leeにより創 設された産業コンソーシアムであり，アメリカのマサ チューセッツ工科大学計算機科学人工知能研究所 (MIT/CSAIL)，フランスに本部を置く欧州情報処理数学 研究コンソーシアム(ERCIM), 日本の慶應義塾大学(Keio), および中国の北京航空航天大学 (Beihang) という 4 ホスト 機関により共同運営されている.

なお, W3Cの標準仕様策定活動は, Working Group (WG), Interest Group (IG), Business Group (BG), Community Group (CG) 等のグループ単位で取組まれる. WGが具体的な技術仕様やガイドラインの策定を行う一方 で, IGは仕様策定の基礎となる要求仕様項目の検討を行う. また，BGはWeb技術のビジネス応用に関する議論を行い， CGはW3C 以外の標準化団体や各種Webコミュニティ等と の連携を含めた基本検討を行う。

\section{Webによるメディア配信とその課題}

\section{1 コンテンツ流通メディアとしてのWeb}

時代とともにWebで扱うコンテンッは多様化しマルチメ ディア対応かつインタラクティブなコンテンツの需要が飛 躍的に増加してきた. その結果, 図1に示す通り, Webコン テンツは，単なる「Webページ」から「Webアプリケーショ ン」へと変遷を遂げ，さまざまな分野に応用されている。 


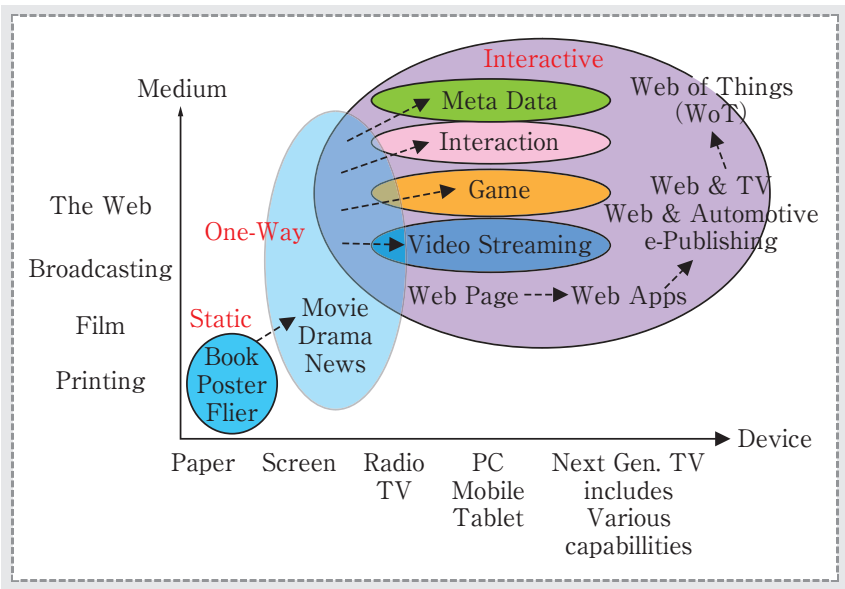

図 1 Evolution of Web Contents

\subsection{HTML5 $と$ と Open Web Platform}

2008年以降, より表現力豊かなWebアプリケーションを 実現するための開発環境としてHTML5が標準化されてい る. HTML5には, 従前の HTMLが持つ基本的な GUI 機能 に対して以下のような機能が追加されており, 音声・動画 等の動的な情報やWeb と利用者との相互的なやりとりに対 応したものとなっているため, さまざまなWebアプリケー ションでの利用が期待されている.

・Video ${ }^{7)}$ およびAudio8)：プラグインを使わずに動画や 音声を再生

\section{- Canvas ${ }^{7)}: 2$ 次元画像描画}

•Drag \& Drop ${ }^{7)}$ : 画像およびテキストの移動・編集

・WebSocket7) 9) 10)：インタラクティブなアプリケー ション構築に必要な,リアルタイムかつ全二重の通信

-Web Storage ${ }^{7)}$ : ローカルクライアント上のWebブラ ウザ内でデータ保存

・Web Workers ${ }^{7)}$ ：Webブラウザ上でのマルチプロセス な扔, W3Cでは, HTML5仕様を中心とする各種Web標 準仕様を含めたWebアプリケーション開発のためのプラッ トフォームのことを“Open Web Platform”と呼んでいる.

\subsection{HTML5によるメディア配信}

近年, Webアプリケーション利用のための入出力端末は $\mathrm{PC}$ に限らず, 携帯電話, 電子書籍等, さまざまな機器が 利用されるようになってきている. また, デジタルテレビ においては，コンテンツ記述とそのレイアウトのために Web 技術が利用されるようになってきており, Webの能 力をさまざまな機器へ対応するよう拡張することが急務と されている.さらに, テレビとタブレット端末等, 複数の 機器を連携させた高度なサービス(いわゆる「セカンドスク リーン」)に対するニーズも高まっており，開発者に負担の かからない形で, ネットワーク越しに複数機器を連携させ る仕組みが必要とされている.

これに対してW3Cでは，まず，各機器の制御に必要な JavaScript APIを体系的に追加することによる機能拡張を

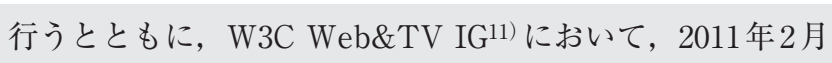
より, Webとテレビの連携に関する検討を進めている. Web\&TV IGは, Web/放送/機器連携に関する技術的議論 のための「場」として, Webサービス抢よび放送サービス の関係性を含む，さまざまな既存の取組みを精査・分析す ることを目的としており，各種サービス提供のための具体 的な要求仕様および想定される解決方法の文書化を行って いる.

\section{4.メディア配信に関連するWeb 標準化議論}

次世代のデジタルテレビに向けて, 既存の放送モデルと は異なる, 新しいインタラクティブなメディア配信モデル が必要とされており, Web技術は，そのユビキタス性およ びスケーラビリティにより，さまざまな機器へのメディア 配信のためのプラットフォームとして期待されている。 そ の一方で, 本格的なインタラクティブ放送を実現するため には，現状のHTML5に不足する機能がいくつかあり，そ れらをHTML5に対する拡張として追加することが提案さ れている．動的ストリーミング配信やコンテンツ保護がそ の例であり，動的ストリーミング配信のための技術である MPEG-DASH (Dynamic Adaptive Streaming over HTTP) に対応するために, Media Source Extensions (MSE) 拡張 13) が検討されており，コンテンッ保護のための技術である Common Encryptionに対応するために, Encrypted Media Extensions (EME) 拡張 ${ }^{14)}$ が検討されている.これ らの拡張を行うことで，HTML5を核とした標準的な枠組 でストリーミング配信とコンテンツ保護が可能となる.

以下では，上記のWeb 標準検討に取組むメディア関連の 各議論グループについて説明する。なお，図2に示す通り， メディア関連の Web 標準化議論は，Web\&TV IG*を中心 として取組まれているため, Web\&TV IGでの議論を中心 に解説する.

\subsection{Web\&TV IG}

\subsubsection{W3Cワークショップでの議論}

Web とテレビのよりよい連携のための検討を進めるにあ たっては, 世界中の関連技術者から広く応用事例や要求項 目に関する意見を集める必要性があるため, Web\&TV IG では，今までに以下の 4 回の公開ワークショップを開催し ている.

（1）東京ワークショップ15)：2010年 9 月 $2 \cdot 3$ 日に慶應義 塾大学三田キャンパスにて開催. Web と機器の連携 全般 (セカンドスクリーン等)について議論.

(2) ベルリン・ワークショップ16)：2011年 2 月 8 ・9日に ベルリンの Fraunhofer-FOKUSにて開催．Web上の ビデオ配信 (動的ストリーミング等)について議論.

（3）ハリウッド・ワークショップ17）：2011年9月 $19 ・ 20$ 日

* 2017年6月にMedia\&Entertainment $\mathrm{IG}^{12}$ として改組の上, 議論継 続中. 


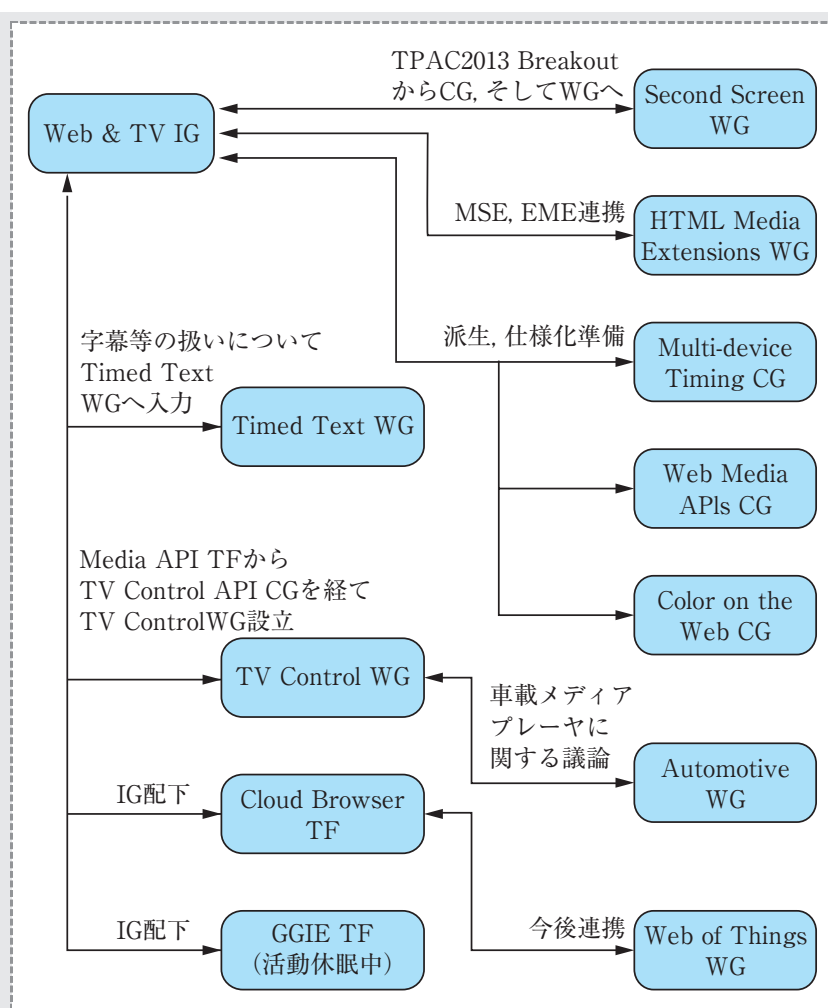

図2 メディア関連議論グループ

にハリウッドのユニバーサルスタジオにて開催. テレ ビコンテンツ (コンテンツ保護等)について議論.

（4）ミュンヘン・ワークショップ18)：2014年 3 月 $12 \cdot 13$ 日 にミュンヘンのIRTにて開催. ハイブリッドテレビ サービスのための各種国際標準 (Hybridcast, HbbTV, ATSC等) とWeb標準との格差について議論.

\subsection{2 タスクフォースによる詳細議論}

Web\&TV IGでは，上記ワークショップでの議論を受け て, 専門委員会 (タスクフォース：TF）を設立した上で各 技術テーマごとに詳細な技術議論を行い, 具体的な形で応 用事例 (Use Cases) および要求仕様 (Requirements) を整 理するとともに, 次世代のテレビサービスに必要とされる 機能と現状の技術との格差の分析を行ってきている．また， その分析結果にもとづいて, どのような形で既存のWeb 標 準を拡張するべきかの検討にも取組んでいる.

以下では, これまでのWeb\&TV IGの取組みとして, 特 に重要な, Home Network TF, Media Pipeline TFおよび Cloud Browser TF の活動内容について概説する.

- Home Network TF ${ }^{19)}$ ：2011年5〜8月の活動期間中, ホームネットワークとWebの統合に関する検討を行 い, その結果を “Requirements for Home Networking Scenarios IG Note” 20) として公開. 議論の成果は, W3CのDeviceAPIs WGおよびWebApps WGに入力.

• Media Pipeline TF21)：2011年9月〜2012年7月の活動 期間中, Web上でのビデオ配信に関する多種多様な問 題分析を行った結果, 動的ストリーミング (MPEG-
DASH）については“MPTF Requirements for Adaptive Bit Rate Streaming Draft ${ }^{22)}$ を公開するとと もに, HTML WGに対して, Media Source Extensions (MSE) 仕様13)への入力を行った。 また，コンテンツ保 護については“MPTF Requirements for Content Protection Draft” 23) を公開するとともに, HTML WG に対して, Encrypted Media Extensions (EME) 仕様 ${ }^{14)}$ への入力を行った. その結果, HTML5.1仕様24)および その拡張仕様 $\left(\mathrm{MSE}^{13)}, \mathrm{EME}^{14)}\right)$ の改善を行った.

・Cloud Browser TF ${ }^{25)}$ : HTML5を利用したメディア 配信において, Set Top Box (STB) 等のシンクライア ントを想定し, クラウドサーバ側でHTML5をレンダ リングする機能 (Cloud Browser)に関して, 基本アー キテクチャおよびユースケースについて検討. Cloud Browserの利用により, 処理能力の劣る旧端末でも, 最新の HTML5機能を利用可能となる.

\subsection{TV Control WG}

Web\&TV IGのMedia API TFから, TV Control API CGを経て，2016年4月にTV Control $\mathrm{WG}^{26)}$ を設立.テレ ビ/ラジオチューナの制御用 API定義について議論. 各種 スマートテレビ規格と Web技術の互換性を考慮するととも に, W3C 以外の標準化規格 (Hybridcast, HbbTV, ATSC 等) とも連携. W3C内では, 車載メディアプレーヤ向け APIに関して, Automotive BGと連携の上, TV Control API案27) を作成.

\subsection{Second Screen WG}

Second Screen WG ${ }^{28)}$ では, Webコンテンツをリモート のディスプレイ上に表示する等, Second Screen（テレビに 対するスマホのような, 二つ目のスクリーン) の操作と同 期に関して検討. Presentation API29) およびRemote Playback $\mathrm{API}^{30)}$ を策定. なお, 図 2 中の「TPAC」とは, 年 1 回開催されるW3Cの技術総会であり，2013年のTPACに おけるBreakout (テーマごとの分科会) にて, Second Screenに関する議論が行われ，CGが設立された.

\subsection{Web Media API CG}

Web Media API CG ${ }^{31)}$ では, メディア配信のために必要 なWeb 技術の最小セット（プロファイル）定義について， 以下の観点から検討.

・ハードベンダのための規範的な API参照

・地域ごとに独自定義されたプロファイルの置き換え

- CTA WAVE (Web Application Video Ecosys-tem) Project ${ }^{32)}$ と連携

\section{5. 今後の展望 : Webへの期待と課題}

Web プラットフォームは, OSやハードウェアに依存し ない, アプリケーション (コンテンツ) 開発・メディア配 信・サービス提供のプラットフォームとして大変有望であ る. 近年, テレビや $\mathrm{PC}$ 等の既存の機器のみならず, ス 
マートフォン等の小型機器がメディア配信のクライアント として一般的に利用されていることを考虑するならば, Webは, 多くのユーザにとってメディアアクセスのスター 卜地点と言える。今後，Webを利用したメディア配信は， 既存の放送の枠を越えて, よりインタラクティブな内容を 持つゲームや仮想現実 (VR)，あるいは各種トレーニング， エンジニアリング，コミュニケーション支援等，さまざま なユースケースへの応用が考えられる.

一方で，具体的なアプリケーション開発をより効率的か つ効果的に進めるためには, 例えば, MSE仕様について, 以下のような機能の追加が必要と考えられる：

・SourceBufferのサイズが不足することを知らせるイベ ント(効率的なバッファリングのために).

・テキストと画像をビデオデータと低コストで同期させ る仕組み(例えば, ActionscriptのcuePointのような 仕組み)。

上記のような問題については, MSE仕様に対する改善提 案33) 35) として HTML Media Extensions WGに提案され ており, 今後, 具体的な仕様改善に取組んでいく必要があ る.また, より先進的なアプリケーションの開発に備え, 以下のような検討にも取組む必要があると考えられる：

・Cloud Browserのサーバ/クライアントモデルにも対 応できるよう，クラウド化に対応したメディアスト リーミングについて検討.

・複数の機器，アプリケーションおよびユーザ間でのメ ディア連携のため, Second Screen WGやMulti-device Timing CGとのより密な連携.

・テレビやスマホ以外のさまざまな機器が相互接続され 協調して動作する環境を想定し, Web of Thingsや, Automotiveの標準化活動とも連携.

\section{6. むすび}

本稿では，まず，Web技術とW3Cによるその国際的標準 化について概観した上で, マルチメディアかつインタラク ティブなWebアプリケーション構築のための開発プラット フォームとして, HTML5を核とした“Open Web Platform” について解説した．さらに，近年ますます広がりを見せる， Webアプリケーション用のさまざまな端末機器の例として テレビに着目した上で, HTML5によるメディア配信の標 準化動向，および今後の展望について述べた。

(2017年7月 21 日受付)

\section{〔文 献〕}

1) W3C, https://www.w3.org/（アクセス : 2012-01-20)

2) http://en.wikipedia.org/wiki/HTML

3) Wikipedia: "HTML", http://en.wikipedia.org/wiki/HTML（アクセ ス : 2012-01-20)

4) D. Ragget, A.L. Hors and I. Jacobs: "HTML 4.01 Specification", https://www.w3.org/TR/html401/（アクセス：1999-12-24)

5) Wikipedia: "HTML5", http://en.wikipedia.org/wiki/HTML5（アクセ

\section{ス : 2012-01-20)}

6) I. Hickson: "HTML 5 A vocabulary and associated APIs for HTML and XHTML", http://www.w3.org/TR/2014/REC-html5-20141028/ (アクセス : 2014-10-28)

7) Google: "HTML5 ROCS", http://www.html5rocks.com（アクセス : 2012-01-20)

8) D. Humphrey, et al.: "Audio Data API, Mozilla", https://wiki. mozilla.org/Audio_Data_API（アクセス：2012-01-20）

9) Wikipedia: "WebSocket", http://en.wikipedia.org/wiki/WebSocket (アクセス：2012-01-20)

10)I. Hickson: "The WebSocket API", https://www.w3.org/TR/ websockets/(アクセス : 2011-12-08)

11) https://www.w3.org/2010/09/webTVIGcharter.html

12)K. Ashimura: "Media and Entertainment Interest Group Charter", https://www.w3.org/2017/03/webtv-charter.html（アクセス：201706-13)

13) M. Wolenetz, et al:."Media Source Extensions", https://www.w3.org/ TR/2016/REC-media-source-20161117/（アクセス：2016-11-17)

14)D. Dorwin, et al.: "Encrypted Media Extensions", https://www.w3. org/TR/2017/PR-encrypted-media-20170316/ (アクセス : 2017-03-16)

15) https://www.w3.org/2010/09/web-on-tv/summary.html

16) https://www.w3.org/2010/11/web-and-tv/summary.html

17) https://www.w3.org/2011/09/webtv/summary.html

18) https://www.w3.org/2013/10/tv-workshop/report.html

19) https://www.w3.org/2011/webtv/wiki/HNTF/Home_Network_TF_ Charter

20) https://www.w3.org/TR/2011/NOTE-hnreq-20111201/

21) https://www.w3.org/2011/webtv/wiki/MPTF/MPTF_Charter

22) http://dvcs.w3.org/hg/webtv/raw-file/tip/mpreq/adbreq.html

23) http://dvcs.w3.org/hg/webtv/raw-file/tip/mpreq/cpreq.html

24)F. Faulkner, et al.: "HTML 5.1", https://www.w3.org/TR/2016/REChtml51-20161101/（アクセス：2016-11-01)

25) https://www.w3.org/2011/webtv/wiki/Main_Page/Cloud_Browser_TF

26)F. Daoust: "TV Control Working Group Charter", https://www.w3. org/2016/03/tvcontrol.html（アクセス：2016-04-14）

27)S. Morris, et al.: "TV Control API Specification", https://www.w3. org/TR/2017/NOTE-tvcontrol-api-20170518/（アクセス：2017-05-18)

28)F. Daoust: "Second Screen Working Group Charter", https://www. w3.org/2014/secondscreen/charter-2016.html (アクセス : 2016-11-03)

29) M. Folz and D.Rttsches: "Presentation API", https://www.w3.org/ TR/2017/CR-presentation-api-20170601/（アクセス：2017-06-01)

30) A. Vayvod and M.Lamouri: "Remote Playback API", https://www. w3.org/TR/2016/WD-remote-playback-20161107/（アクセス：201611-07)

31) M. Vickers: "Web Media API CG Home Page", https://www.w3.org/ community/webmediaapi/（アクセス：2017-03-24)

32) https://standards.cta.tech/kwspub/wave/WAVE_Web_ Application_Video_Ecosystem__Definition_of_Scope_FINAL.pdf

33)K. Hoya, S. Nishimura and S. Harada: "MSE/EME: Potential implementation issues on TV sets a Case Study of IPTV Forum-Japan Player", https://www.w3.org/2011/webtv/wiki/images/6/ 66/Webtv_mse_eme_iptvfj_player_20151026.pdf (アクセス：2016.09-19) 34) https://github.com/w3c/media-source/issues/40

35) https://github.com/w3c/media-source/issues/41

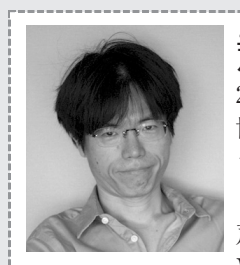

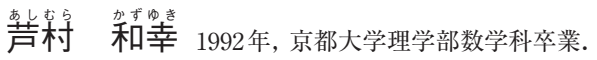
2005 年, 奈良先端科学技術大学院大学情報科学研究科 博士後期課程単位取得退学. 1992 年, NTTソフト ウエア (株) 入社. (株) ATR 音声翻訳通信研究所, (株) アルカディア, JST/CREST「表現豊かな発話音 声のコンピュータ处理」研究員を経て，2005年より， W3C (World Wide Web Consortium)にて, Web技術 の産業応用に関する各種国際標準化活動 (音声・マルチモーダル, Web と TV, Webと車, NFC, Geolocation等) に従事. 現在, Web of Things (WoT: WebとIoT), Media \& Entertainment (Webとストリーミングメ ディア)に関するWeb標準化を担当. W3C Project Specialist兼務. 慶應 義塾大学大学院政策・メディア研究科特任准教授. 博士 (工学). 